\title{
Samuel Junod, Agrippa d'Aubigné ou les misères du prophète
}

\section{Dario Cecchetti}

\section{(2) OpenEdition \\ 1 Journals}

\section{Edizione digitale}

URL: http://journals.openedition.org/studifrancesi/7887

DOI: 10.4000/studifrancesi.7887

ISSN: 2421-5856

\section{Editore}

Rosenberg \& Sellier

\section{Edizione cartacea}

Data di pubblicazione: 1 juillet 2009

Paginazione: 383-384

ISSN: 0039-2944

\section{Notizia bibliografica digitale}

Dario Cecchetti, «Samuel Junod, Agrippa d'Aubigné ou les misères du prophète», Studi Francesi [Online], 158 (LIII | II) | 2009, online dal 30 novembre 2015, consultato il 12 janvier 2021. URL: http:// journals.openedition.org/studifrancesi/7887 ; DOI: https://doi.org/10.4000/studifrancesi.7887

Questo documento è stato generato automaticamente il 12 janvier 2021.

\section{(c) (i) $\odot$}

Studi Francesi è distribuita con Licenza Creative Commons Attribuzione - Non commerciale - Non opere derivate 4.0 Internazionale. 


\title{
Samuel Junod, Agrippa d'Aubigné ou les misères du prophète
}

\author{
Dario Cecchetti
}

\section{NOTIZIA}

SAMUEL JUNOD, Agrippa d'Aubigné ou les misères du prophète, Genève, Droz, 2008 («Cahiers

d'Humanisme et Renaissance», vol. 83), pp. 352.

1 Come S. Junod indica in apertura del suo interessante lavoro, «Aubigné e prophète sono due parole, due istanze della complessa figura letteraria costruita da Agrippa d'Aubigné nella sua opera, che hanno un destino comune, nella critica letteraria e nell'immagine convenzionale che ci facciamo del poeta dei Tragiques» (p. 11). Il presente saggio si propone anzitutto di sbarazzare il campo dai luoghi comuni della biographie prophétisante albineana, volta a identificare stilemi e strutture profetizzanti dell'opera poetica con un atteggiamento esistenziale, nel tentativo di «ancorare la questione all'ambito di una strategia letteraria e di una poetica». Se è vero infatti che esiste, da parte di Aubigné, la volontà di trasmettere un messaggio che si vuole 'profetico', nel quadro di un costante impegno politico e religioso, è anche vero che il ricorso al linguaggio e ai modelli profetici (biblici) sfocia in un vero e proprio sistema retorico. Ben sottolinea l'A. come «la figura profetica sia costruita mediante la messa in opera di strategie che si rifanno alla creazione letteraria: l'imitazione, l'ethos»; e come «essa sia anche un effetto della ricezione, della scelta del lettore di accordare all'autore del discorso, a prezzo di uno slittamento sottile, il prestigio che deriva al personaggio discorsivo inventato da questo discorso stesso»(p. 12). Il libro è suddiviso in due parti. Nella prima (La figure prophétique en aval et en amont des "Tragiques", pp. 35-138) viene ricostruita la ricezione di Agrippa d'Aubigné - ricezione in cui si configura l'immagine di Aubigné-profeta - a partire dal discorso critico che si costruisce nell'Ottocento sull'opera dello scrittore ugonotto. È con Sainte-Beuve, infatti, che viene abbozzato il ritratto di Aubigné dans une posture prophétique. D'altra parte è nell'Ottocento che la rinascita dell'opera di Aubigné si accompagna a un effetto di amplificazione della sua 
étrangeté e all'affermarsi di un mythe personnel che è appunto il mito del profeta protestante. Senza contare che Hugo nel comporre una lista di novantacinque poeti, fra i più importanti dell'umanità, include Aubigné in questo elenco che comprende tutti i grandi profeti veterotestamentari e sottintende l'equivalenza poeta e profeta. In questa prima parte viene inoltre raffrontata la posture prophétique di Aubigné con quella di Lutero e Calvino nel quadro della teologia e dell'ecclesiologia riformata nel Rinascimento. Nelle seconda parte (L'èthos' prophétique: la création d'une figure de l'énonciation dans les “Tragiques”, pp. 141-310) l'A. esamina le modalità con cui questa posture assume le caratteristiche di figura retorica, nella convinzione che «non si possa determinare il senso di un discorso qual è quello dei Tragiques senza qualificare la sua enunciazione, in termini di modalità di parola, di posizione morale, di forza pragmatica, di discorso assunto o riportato» (p. 27). 